\title{
Areté, Ethos académico, TIC's y pandemia en México
}

\author{
Areté, Academic Ethos, ICTs and pandemic in Mexico
}

MARÍA MARGARITA FLORES SANTIAGO

Centro de Estudios Latinoamericanos de la Facultad de Ciencias Políticas y Sociales, Distrito Federal, México (margaritaf@politicas.unam.mx)(https:/orcid.org/0000-0002-4272-1063)

\section{RESUMEN}

En esta investigación se pretende explicar el arte de enseñar aludiendo a algunas concepciones filosóficas y pedagógicas en el ejercicio y la formación de estudiantes. Se aspira a relacionar dos términos griegos Areté, Ethos con el arte de enseñar. Y cómo la carencia de ambos incide directamente en el proceso enseñanzaaprendizaje. Se muestra el efecto que puede tener en los estudiantes la resistencia al cambio y la necesidad de capacitación en el conocimiento y apropiación de las Tecnologías de la Información y la Comunicación (TIC'S). Se utiliza el método deductivo en un estudio de caso en la Facultad de Ciencias Políticas y Sociales de la Universidad Nacional Autónoma de México. Se hace uso datos oficiales, diversos recursos digitales y se aplica una encuesta con base en temas relevantes sobre el conocimiento y apropiación de las Tecnologías de la Información analizadas desde el paradigma de la codificación. Los resultados indican que la atención se debe enfocar en el ethos de enseñar cuando se producen los cambios considerando tres momentos: la planeación, el ejercicio y la improvisación.

\section{ABSTRACT}

This research aims to explain the art of teaching by alluding to some philosophical and pedagogical conceptions in the exercise and training of students. The aim is to relate two Greek terms Areté, Ethos and their relationship with the art of teaching. And how the lack of both directly affects the teaching-learning process. The effect that resistance to change, the need for training in knowledge and appropriation of Information and Communication Technologies (ICT) can have on students is shown. The deductive method is used in a case study at the Faculty of Political and Social Sciences of the 
National Autonomous University of Mexico. Official data, various digital resources are used and a survey is applied based on relevant topics about the knowledge and appropriation of Information Technologies that are analyzed from the coding paradigm. The results indicate that attention should be focused on the ethos of teaching when changes occur, considering three moments, planning, execution and improvisation.

\section{PALABRAS CLAVE / KEYWORDS: ARETÉ}

Areté; Ethos; TIC'S; planeación; arte de enseñar / Ethos; ICT; planning; art of teaching.

\section{INTRODUCCIÓN}

A lo largo de los siglos, en los escritos de los filósofos se puede leer su interés en la educación, por ejemplo, Platón percibe que la educación es el eje de todo, por ello menciona “... según hacia dónde uno se dirija, partiendo de la educación, de ese modo sea lo que venga después" (1988, §425c). La sociedad que el gobierno desea tener se proyecta en las políticas educativas y en particular en los contenidos de los libros de texto de la educación obligatoria y el diseño de los planes de estudios de las instituciones de educación superior (IES). Sin embargo, el docente no debe evadir su responsabilidad en este proceso, pues es un compromiso cuatripartita en el que participan Gobierno-maestros-estudiantes-padres de familia. El tipo de sociedad a la que se aspira es la que se forma en las aulas.

Es probable que no se cuente con la infraestructura deseable, pero eso no obsta para reinventarse y buscar alternativas (Prensa total, 2019), (Sistemasumma, 2020) y tampoco significa quitarle responsabilidades al gobierno.

El arte de enseñar está estrechamente relacionado con la vocación, la pasión, la creación, la flexibilidad, el compromiso, la apropiación de métodos, instrumentos o herramientas que ayuden al estudiante a pensar, reflexionar, proponer, disfrutar, generar e interpretar y entender su realidad, en ese sentido, "la educación tiene dos fines: por un lado, formar la inteligencia; por el otro, preparar al ciudadano”. (Russell, 1983, p.195)

Si bien es responsabilidad de las autoridades gubernamentales y educativas planificar qué se enseñará los profesores pueden trascenderlo, reinventándose, integrando al estudiante en su formación, y mostrando empatía por quienes se van rezagando.

El profesor debe planear sus actividades pensando en posibles contingencias, debe tener una mente abierta a seguir aprendiendo, debe mostrarse solidario hacia quienes no tienen los medios, las capacidades o las habilidades deseables para dedicarle más tiempo y lograr integrarlos. Debe aprender a ver los obstáculos como oportunidades para seguir creciendo. 


\section{CONTINGENCIA}

Para finales del año 2019 en los medios de información empezaron a circular noticias de una enfermedad desconocida pero mortal. Las medidas tomadas en Wuhan, China, quizá parecieron exageradas, graciosas, preocupantes, pero nunca parte de la realidad global. El 28 de febrero de 2020 se dio el primer caso en México de la enfermedad denominada COVID-19. El 23 de marzo las autoridades decidieron que iniciaría la jornada nacional de sana distancia, que terminaría el 19 de abril de 2020. Qué lejos se estaba de imaginar que esa cuarentena se alargaría por más de un año.

Los estudiantes con plan semestral estaban a la mitad del camino, y los de plan anual a punto de terminar. ¿Qué hacer?, ¿Cómo continuar y terminar los cursos? ¿Cómo contactarlos? ¿Cómo evaluarlos? ¿Cómo pasar de una enseñanza tradicional a una virtual?

Cuánta razón tenía Rousseau (s/f) al decir “Poco diré de la importancia que tiene una buena educación. Tampoco me detendré a demostrar que la usada hoy es mala: mil lo han demostrado ya... todavía se sigue olvidado el arte de formar a los hombres, que es la primera de todas las utilidades" (p.4).

Sí, la contingencia sanitaria puso en evidencia la fragilidad del ser humano, de los gobiernos y de las instituciones, en particular de las educativas y de los profesionales dedicados a la educación.

En tiempos normales la matrícula en la educación superior es baja en comparación con la educación básica', la eficiencia² escolar es mayor en la Ciudad de México (46\%); Aguascalientes (42\%); Querétaro (42\%) y Yucatán (40\%). Mientras que los estados con menor eficiencia son Chiapas (12\%), Oaxaca (14\%); Guerrero (17\%); Veracruz (18\%) y Michoacán (18\%). (Secretaría de Educación Pública (SEP), 2020, p.15). Esos datos muestran la brecha educativa tan marcada en el territorio mexicano, los estados del sur han sido los más pobres y los más afectados, paradójicamente son los más ricos en recursos naturales. En tiempos normales la eficiencia terminal en esos estados no es buena pero con la pandemia la situación empeoró. Por ejemplo, el abandono escolar en el periodo 2017-2018 fue de 0.5\%; de 2018-2019 aumentó a $0.7 \%$, pero se mantuvo para el periodo siguiente. Los estados con mayor deserción escolar fueron los más pobres: Michoacán, Veracruz, Oaxaca, Chiapas y Guerrero (SEP, 2020, p.27).

Parecía que las cosas cambiarían en el siguiente ciclo escolar (2020-2021), pero empeoraron 9.6\% de estudiantes desertó en todos los niveles de educación, es decir, 5.2 millones. ¿Los motivos? COVID-19, problemas económicos, falta de comunicación con sus profesores, carencia de equipo, falta de conexión a Internet. A ellos se sumaron 3.6 millones que no se inscribieron porque tenían que trabajar. (Instituto Nacional de Estadísticas y Geografía, (INEGI), 2020, p. 13)

\footnotetext{
De una población total 36,518,712 estudiantes, el 69.2\% corresponde a la educación básica; $14.1 \%$ a la media superior; $11.1 \%$ a la superior y el 5.6\% a la capacitación para el trabajo (Secretaría de Educación Pública (SEP), 2020, p.12)

2 La eficiencia es definida por la Secretaría de Educación Pública (2020) como el "número de alumnos que egresan de un determinado nivel educativo en un ciclo escolar, por cada cien alumnos inscritos en la cohorte escolar inicial del mismo nivel" (p.8).
} 
La brecha digital asestó un duro golpe a los estudiantes con escasos recursos, a los profesores que no conocían las Tecnologías de Información y Comunicación (TIC l S) y a las instituciones educativas que no previeron una contingencia como ésta. En ese sentido cuánta razón tenía Montesquieu al decir “en el régimen republicano es en el que se necesita de toda la eficacia de la educación... pero la virtud política es la abnegación, el desinterés, lo más difícil que hay." (Montesquieu, 2010, p. 33). En efecto, la falta de abnegación y desinterés de los funcionarios públicos se reflejó en una educación deficiente durante la pandemia. En el Plan Nacional de Desarrollo (PND) se estableció como objetivo la cobertura de Internet para todo el territorio nacional, mediante la instalación de internet inalámbrico, conexión en espacios públicos comunitarios. Presidencia de la República, 2019), pero no se pensó y por lo tanto, tampoco se contempló la necesidad de dotar de infraestructura a las instituciones educativas, como equipo de cómputo, Plataformas educativas, recursos multimedia, etc.

¿Se ha logrado el objetivo expuesto en el PND? No. Según los datos presentados por la Secretaría de Gobernación se identificaron 136,574 sitios públicos, de ellos se seleccionaron como prioritarios 19,041 (el 13.9\%), (Secretaría de Gobernación, 2021). Sin embargo, de acuerdo a los datos de la Secretaría Comunicaciones y Transportes solo se conectaron 1,648, es decir, el 8.6\%, los estados más beneficiados fueron Chiapas con 498 de 2,999, es decir 16\%; Oaxaca con 418 de 3161, es decir el 13\%; Puebla con 104 de 1649, 6.3\%; Guerrero con 150 de 2,468, 6\%; y Veracruz, con 197 de 3972, 4.9\% (Gobierno de México, 2019). Queda mucho por hacer.

De ahí que la contingencia sanitaria aceleró un problema que tarde o temprano se presentaría, pero no de manera tan abrupta y sorpresiva: la necesidad de realizar las actividades académicas en línea. Se debía hacer con destreza, paciencia, habilidad, capacidad y sobre todo con mucha dedicación y tiempo, eso que lo que los griegos denominaban Areté, es decir, habilidad para realizar una tarea determinada con excelencia y para lograrlo se requiere dedicación exclusiva. De ahí que Platón (1988) en la República afirmara que “... es imposible que una sola persona ejerciera bien muchas artes" (§374a) porque una sola actividad, profesión o tarea implicaría conocimiento, esfuerzo, tiempo, compromiso, responsabilidad, etcétera. Por ejemplo, para ser un atleta olímpico se requieren muchos años de preparación, ejercitación del cuerpo, de la mente, tener buenos hábitos alimenticios, renunciar a diversiones y acciones que pueden afectar su desempeño.

De ahí que, el poseer un gimnasio no hace del dueño un atleta, “... en lo que concierne a las demás herramientas, ninguna de ellas convertirá en atleta o en artesano a quien la tome, ni será de utilidad a quien no haya adquirido los conocimientos propios de cada arte ni se haya ejercitado adecuadamente en su manejo." (Platón, 1988, §374d) Probablemente se posea tecnología de punta, pero se desconocen las herramientas, recursos o aplicaciones que me permitan enseñar y evaluar de manera lúdica, atractiva, eficaz, significativa e inclusiva, esto último implica tener una actitud empática e integrar a todos los estudiantes, incluso a quienes no poseen los medios como Internet o equipo de cómputo.

Es en este punto donde entra el ethos, es decir, la apropiación de la enseñanza como forma de vida, en el sentido de pertenencia, de compromiso, de pasión, de gusto, de sacrificio, de empatía. Implica mantenerse al día con todo aquello que mejore la transmisión de conocimiento, que lo enriquezca. No son una serie de reglas impuestas de manera vertical, sino un compromiso mutuo, en el que el estudiante se sienta integrado, como bien menciona Freire (2007) “La educación dialogal (diálogo) opuesta a la educación monologal" (p. 8,9). El estudiante no es un ser pasivo que solo sirve como bodega de almacenamiento, es 
un ser creativo, propositivo, pensante.

Ahora bien cuál es la relación entre ethos y docencia? Max Weber en su libro El político y el científico, describe la diferencia entre el político por profesión (vive de la política) y el político por vocación (vive para la política). El político por profesión ve a la política como un medio para sostener su vida, es decir como una forma de tener ingresos que le permitan vivir de manera desahogada. Mientras que el político por vocación hace de la política su vida "en un sentido íntimo; o goza simplemente con el ejercicio del poder que posee, o alimenta su equilibrio y su tranquilidad con la conciencia de haberle dado un sentido a su vida, poniéndola al servicio de algo" (Weber, s/f, p.7). Eso mismo sucede con la educación, hay profesores que ejercen su profesión con pasión y hay quien lo hace por obligación. Ambos reciben un sueldo, pero mientras que unos invierten mucho tiempo en la preparación de su clase, en pensar y resolver las posibles dudas, en calificar y corregir las tareas, en diseñar estrategias para que los alumnos pueden mejorar su aprovechamiento; otros improvisan y solo les interesa cumplir con un horario y seguir con su rutina, pierden de vista los objetivos del curso, los contenidos y por supuesto a los estudiantes.

En otras palabras, uno la ejerce para salir avante de sus problemas económicos de manera holgada, mientras que el otro tiene un sentido de pertenencia, de logro, de satisfacción al ejercerla, hace de la enseñanza su vida.

Resistencia, capacitación y aprendizaje en la UNAM. Desde 2010 la UNAM vislumbra la necesidad de actualizar y capacitar a su planta docente, por ello invitó a los profesores al Diplomado denominado Aplicaciones de las TIC 䀚 S para la enseñanza. Era una propuesta innovadora, por ello a los profesores les asaltaron una serie de dudas que una vez aclaradas dieron lugar a otras, para finalmente dar paso a la impotencia, resistencia, juicios de valor, temor a lo desconocido, incomprensión de su necesidad y pertinencia, ignorancia de su explotación, justificación de su inoperancia, en concreto la pregunta generada fue ¿para qué cursar un Diplomado de ese tipo en una institución de educación superior como la UNAM?

\section{METODOLOGÍA}

Se realiza un acercamiento al campo y al objeto de estudio a través de la estrategia metodológica de la conversación, con una entrevista semiestructurada con base en temas considerando el siguiente Supuesto: Los sujetos de la investigación no tenían claro el significado de TIC'S, plataforma educativa, el constructivismo y su relación con la tecnología.

INSTRUMENTO DE RECOLECCIÓN DE LA INFORMACIÓN:

Se diseña una encuesta con base en temas centrales referidos a Aplicaciones de las TIC'S para la enseñanza.

¿Cómo insertarlo, usarlo y/o explotarlo en áreas tan diferentes como las Ciencias Sociales; Ias Ciencias Biológicas y de la Salud; las Físico Matemáticas e Ingenierías; las Humanidades y Artes?

- ¿Para qué alterar lo que ha funcionado por tantos años? 
- ¿Para qué invertir tiempo en su inserción en la enseñanza si es del dominio público la brecha digital que existe en México y como consecuencia la insuficiente infraestructura para su éxito?

- ¿Para qué adquirir habilidades digitales, si posiblemente al final del camino ni siquiera se emplearían para mejorar la enseñanza?

- ¿Cómo sacar tiempo para explorar y explotar la tecnología?, ¿cómo conocer las habilidades digitales y creativas de los estudiantes y canalizarlas para generar conocimiento o interpretar y/o hacer más accesible el existente?

- ¿Cómo apropiarse de habilidades digitales y subordinarse a los objetivos del programa de nuestra asignatura?

- ¿Cómo hacer tangible, accesible y comprensible términos tan abstractos manejados en disciplinas como filosofía, filosofía política, ciencia política o sociología?

\section{ANÁLISIS}

Se analizaron los discursos desde el paradigma de la codificación e interpretación hermenéutica. De esta forma se generaron las unidades conceptuales que se agruparon en tres ideas centrales (categorías temáticas) que más abajo se describen: La planeación, el ejercicio y la improvisación.

Las preguntas señaladas fueron contestadas a lo largo del Diplomado, por tanto se fue aumentando el acopio de la información hasta saturar la misma. Es determinante la atención, paciencia y dirección de los asesores, el compromiso, responsabilidad y puntualidad de los estudiantes y la presteza, certeza, ingenio y planeación de los autores intelectuales del mismo.

\section{RESULTADOS}

A partir del análisis de la información y agrupación de las ideas en categorías temáticas se concluyó que el personal docente se niega y toma distancia del uso de la Tecnología por diversos motivos, entre ellos:

1. Resistencia frente a la tecnología.- Pensar que a cierta edad ya no se puede aprender a usar las TIC'S. Resistencia a verse como alumnos y a iniciar un proceso de aprendizaje que les permitirá enriquecer no su visión de la enseñanza, sino la visión del estudiante con respecto a lo enseñado. En ese sentido Rousseau, menciona algo muy real para estos tiempos: "Los protestantes están generalmente mejor instruidos que los católicos. Es muy natural: la doctrina de los primeros exige la discusión; la de los segundos, sumisión. El católico debe aceptar la decisión que le dan; el protestante debe aprender para decidir." (Rousseau, 1965. p.77) El aprendizaje y capacitación continua es muy importante para decidir y para no anquilosarse en la comodidad de lo conocido por miedo a lo desconocido.

2. Juicios de valor.- Se crean y se arraigan sobre falsos fundamentos: el empobrecimiento del conocimiento con el uso excesivo de las TIC'S, su corto alcance al no poseer todos los alumnos su computadora personal, su fracaso por la precaria infraestructura dentro de la institución, la poca participación de los estudiantes por sus múltiples ocupaciones, tareas, actividades, etcétera, y una mayor individualización. 
3. Desconocimiento de su uso.- La mayoría de los profesores son parte de una generación denominada migrantes digitales, si bien es cierto que conocen y utilizan las TIC'S lo hacen de manera limitada a diferencia de los jóvenes alumnos denominados nativos digitales quienes desde muy pequeños han estado inmersos en el mundo digital. Ante esta desventaja de conocimientos tecnológicos es importante reconocer las carencias y abrirse a las nuevas formas y métodos de enseñanza porque "La educación es un acto de amor, por tanto, un acto de valor". (Freire, 2007, p.92). Si bien los estudiantes nacieron en una cultura digital y pasan mucho tiempo conectados a Internet, no lo hacen usando las aplicaciones educativas, sino en sus redes sociales, como lo muestran los datos del INEGI (2020) al dar el porcentaje 91.5\% de usuarios que lo utilizan para entretenimiento. En diez años el uso de la tecnología no cambió, una década antes, en 2009, la UNAM realizó un estudio sobre ese asunto y se concluyó que el "90 por ciento de sus estudiantes utiliza frecuentemente las tecnologías de la información y la comunicación (TIC'S) en sus actividades cotidianas." (El Informador, 2011, §1). Pero no en sus actividades académicas. De hecho, desconocen las aplicaciones y recursos académicos.

4. Insuficiente infraestructura.- La institución no cuenta con el equipo suficiente de computadoras para la población estudiantil, es decir el equipo de cómputo de las áreas de informática es directamente desproporcionado al número de estudiantes. Si a ello se le suma que buena parte del equipo no está actualizado el escenario se torna poco alentador.

5. Ausencia del ethos académico.- Si a todo lo anterior se le suma la ausencia de un sentido de compromiso y pertenencia a la responsabilidad educativa, entonces los factores señalados se convierten en obstáculos infranqueables para apropiarse de las habilidades digitales y hacer frente a los nuevos retos. El ethos académico implica darse la oportunidad de innovar y apropiarse de cualquier herramienta que permita enriquecer aún más la formación de los estudiantes, aunque ello signifique un mayor esfuerzo, trabajo, inversión de tiempo y confianza en su éxito pese a las circunstancias adversas.

Por tanto, el ethos académico incluye transmitir en el estudiante la pasión por lo enseñado, conducirlo hacia una nueva forma de apropiación, generación e interpretación del conocimiento. Significa romper con esquemas que mantienen al estudiante anquilosado a viejas formas de reproducción del conocimiento en el que el profesor decide qué enseña, y cómo lo enseña, y qué debe memorizar el estudiante para ser evaluado de manera aprobatoria. Implica entonces, darnos la oportunidad de conocer otras herramientas que enriquecerán la formación de los alumnos y permita encauzar el conocimiento y canalizar las habilidades digitales del alumno.

\section{DISCUSIÓN}

Al despojarse de prejuicios y temores los docentes se pudieron percatar de la generosidad y pertinencia del uso de las TIC'S cuando hay una buena dirección y entendimiento de su conveniencia.

Su uso hace posible una atención más personalizada de los alumnos, con herramientas como los "Foros" se da una mejor integración de aquellos que por timidez y no por ignorancia, no se permiten participar en las clases presenciales.

Así, contrario a lo que se piensa, ante una sociedad cada vez más individualizada el uso adecuado de las TIC'S permite una mayor interacción entre los alumnos, así como una mejor 
integración y valoración del individuo, cosa que parece imposible en cursos presenciales en los que el tiempo no permite la participación de todos los alumnos cuando los grupos exceda de 30.

Al realizar materiales como "videos" los alumnos muestran la percepción de sus lecturas y de lo aprendido en clase y lo ejemplifican para una mejor comprensión no sólo de sus pares educativos sino para un público más abierto. Es decir, trascienden su conocimiento, no memorizan las lecturas, frases o aportaciones de los autores para un examen que les merecerá una calificación aprobatoria pero su retención y comprensión será efímera, más bien, en unos pocos minutos explican, aplican y sustentan lo que puede ser refutado por un público muy grande.

Con las Wiki, afinan sus habilidades de investigadores y aprenden a redactar con soltura al realizar sus trabajos y/o ensayos. Por si fuera poco, previo a su elaboración debió existir el trabajo colaborativo en el que cada miembro del equipo enriqueció el trabajo final no mediante la sumatoria de pequeñas fracciones sino con la participación constante en la redacción, presentación, investigación y corrección del mismo.

Así, mediante el uso de las TIC'S, el tipo de conocimiento generado o interpretado ha trascendido el tiempo y el espacio, motivo por el cual el estudiante se siente incentivado para seguir creando, participando y esforzándose porque el fruto de su esfuerzo no es efímero, perdura a través del tiempo.

Visto está que el uso de las TIC'S no empobrece ni demerita el papel del docente, más bien lo diversifica.

Los Diplomados diseñados por la UNAM para conocer, explorar y explotar las TIC 䀚 S han mostrado que para que cualquier empresa tenga éxito debe estar bien pensada, estructurada y con objetivos claros y factibles. Al cursarlos, el docente en su papel de alumnos puede percibir cómo se replican las prácticas, excusas y actitudes -por ejemplo: apatía, ausencia y crítica sin fundamento- que como docentes reprueban y combaten. Aunque también se refleja el sentido de compromiso, disciplina y honestidad.

Estos cursos de actualización docente permiten conocer la interrelación existente entre disciplinas que parecen no converger, se aprende que lo que para algunos es su insumo primario para otros es un elemento complementario.

Trabajar a marchas forzadas, los desvelos y la ansiedad generada durante este tipo de cursos bien vale la pena cuando se puede aplicar lo aprendido y hay una respuesta positiva, creativa y propositiva por parte de los alumnos.

Es innegable que la inserción de las TIC'S en la enseñanza conlleva tiempo, esfuerzo planeación y pertinencia, pero también es innegable que una buena ejecución permite cosechar grandes satisfacciones así como empezar a sembrar conocimiento no perecedero.

Lo aprendido en los Diplomados ${ }^{3}$ ayudó a derrumbar posturas basadas en prejuicios sobre el uso de las TIC'S en la enseñanza, no con palabras persuasivas, sino con la práctica

3 El segundo Diplomado se efectuó en 2016, se llamó: TIC'S para el desarrollo de habilidades digitales en el aula se diseñó y programa por la Dirección General de Tecnologías de la Información y Comunicación y la Facultad de Ciencias Políticas y Sociales de la UNAM. 
y buena acogida de los estudiantes quienes pese a no contar con la infraestructura mínima necesaria, se esforzaron y agotaron recursos con el fin de ver terminada su formación con un producto realizado por ellos mismos, en el que gozaron de libertad para dar rienda suelta a su creatividad y verter sus conocimientos en un producto tangible, durable y accesible. La inserción de las TIC'S a la educación a “una educación que conlleve al hombre en una nueva posición frente a los problemas de su tiempo y de su espacio... de estudio y no de mera, peligrosa y molesta repetición de fragmentos, afirmaciones desconectadas de sus mismas condiciones de vida". (Freire, 2007, p. 88)

\section{LAS TECNOLOGÍAS DE LA INFORMACIÓN Y COMUNICACIÓN (TIC) EN EL DISEÑO DEL CURSO}

1. Las habilidades y competencias digitales del estud-iante y del profesor para generar recursos educativos y de larga duración.

2. La existencia de aplicaciones y softwares gratuitos o accesibles a todos los estudiantes.

3. Que cuenten con equipo de cómputo (laptop, escritorio); teléfono o tableta con acceso a Internet.

4. Que su equipo cuente Software (Editor de textos (Word); Presentador de diapositivas (Power Point); Visor para archivos en formato PDF; Editor de imágenes (Picnik); Navegador Internet Explorer 7 o Mozilla Firefox 3.01; Reproductor de vídeos (Quicktime); Editor de audio (Audacity); Editor de video (Windows Movie Maker); Youtube; Blip.tv; Programa Cmaps)

5. Que conozca y sepa utilizar la aplicación Piktochart (para realizar infografías)

6. Que conozca y sepa utilizar la aplicación Timeline (para crear líneas de tiempo)

7. Que conozca y sepa utilizar la aplicación Powtoon (para crear videos de animación en línea, significa que no necesita descargar algún software)

8. Que pueda crear, diseñar y alimentar su sitio web mediante un Blog.

9. Que pueda crear o modificar el contenido de una Wiki.

10. Que tenga acceso y sepa navegar en la Plataforma educativa (Moodle)

11. Que cuente con correo de Gmail para que pueda tener acceso a Meet)

12. Que sepa utilizar la aplicación "Drive" para que pueda trabajar en google docs y compartir documentos con el profesor para ser editados.

13. Que tenga cuenta de Dropbox para compartir por eso medio documentos que no se pueden compartir de otro modo.

Pareciera que son muchos los recursos digitales, softwares y aplicaciones, sin embargo, 
comparado con los existentes son una pequeña muestra representativa. Ahora bien, el estudiante no está obligado a conocer todos y cada uno de esos recursos. Algunos serán obligatorios como tener una cuenta de correo electrónico, crear un Blog, trabajar en Google Drive de manera colaborativa, tener una cuenta de Dropbox y navegar en la Plataforma educativa (Moodle). Del resto puede escoger alguna aplicación para la elaboración de su trabajo final lo puede hacer de manera individual o por equipo.

Se cree que haber nacido en la era digital significa que las nuevas generaciones conocen, entienden y manejan los recursos digitales educativos. Sin embargo, eso resulta totalmente falso y la pandemia lo dejó más que claro. El desconocimiento de los recursos educativos y la carencia de equipo o la falta de acceso a Internet generó en todos los niveles, estrés, desesperación y abandono escolar. Aunque el abandono escolar fue más visible en los niveles básicos. Eso indica que si bien los jóvenes invierten mucho tiempo en sus dispositivos móviles conectados a Internet pero lo hacen en sus redes sociales, como Facebook, Twitter, Instagram y Tik Tok.

Ante este panorama, como facilitadores al acceso de las herramientas arriba indicadas, en el aula virtual ${ }^{4}$ los estudiantes deben encontrar tutoriales, videos y los sitios de internet oficiales de las aplicaciones y recursos.

\section{PLANEACIÓN}

Para que el conocimiento sea significativo, atractivo, lúdico, no hay lugar para las improvisaciones.

En las clases tradicionales se cae en malos hábitos que vuelven las clases tediosas, rutinarias, aburridas, como bien lo define Weber (s/f) “... se da el caso de ser alguien un sabio excepcional y al mismo tiempo un catastrófico profesor" (p.42), esto indica que no es suficiente saber mucho, ser muy brillante, es necesario saber transmitir ese conocimiento. Los estudiantes entran a clase obligados por el plan de estudios y por las reglas del juego (asistencia y puntualidad obligatoria, no se puede tomar la palabra a menos que el profesor lo permita, en el mejor de los casos el maestro dicta la clase, en el peor de los escenarios la improvisa), el conocimiento se reduce a la memorización de datos perecederos, a trabajos finales o a exámenes para evaluar su conocimiento. Quizá tenga una muy buena evaluación, pero una mala percepción de los contenidos. Y si no pudo memorizar se sentirá culpable y pensará que la incapacidad para entender es suya y no a las carencias pedagógicas del profesor para hacer atractiva su clase, como bien lo dice Bronowski (1978) "Mucha gente está convencida de que no pueden entender los objetos técnicos. O de que los números no les entran... Suponiendo que les interesen las matemáticas, por ejemplo, su interés ha sido generalmente ahogado por una enseñanza rutinaria" (p.4) De ahí se infiere que si bien son importantes los objetivos y los contenidos de la asignatura, la forma en que se llega a ellos se ha vuelto determinante.

\footnotetext{
4 En la Universidad Nacional Autónoma de México UNAM) los profesores gestionan sus aulas virtuales en la Coordinación de Tecnologías para la Educaciónh@bitat puma que depende de la Dirección General de Cómputo y de Tecnologías de Información y Comunicación.
} 
Debido a lo anterior, es indispensable diseñar y planear muy bien las clases virtuales. Se debe conocer la población a la va dirigido el curso, semestre o año y cantidad de estudiantes, recursos a utilizar y formas de evaluación. El docente debe determinar cómo distribuirá el tiempo de acuerdo a los contenidos temáticos y los objetivos.

Por otra parte, lo primero que debe encontrar el estudiante al entrar a su aula virtual es un libro en el que se establezcan los objetivos, las unidades temáticas y la bibliografía.

El aula debe estar diseñada por fechas y unidad temática, consta de recursos (como Chat para comunicarse cuando trabajen por equipo y Foros para participar con respuestas a en las diferentes preguntas previamente redactadas) con instrucciones claras y precisas. Asimismo, se señalará la fecha en que estarán activos y el porcentaje que corresponde a su participación. En cada unidad encontrará la bibliografía vinculada a su sitio URL.

Los estudiantes realizarán un control de lectura por unidad, mismo que subirán y descargaron en la Plataforma en el recurso denominado Tareas, para la revisión del profesor, mismo que después de leerlos y corregirlos los regresará por el mismo medio con su evaluación o posible corrección. Cuando el control ha sido aprobado el estudiante podrá subirlo a su Blog personal.

Para el trabajo final se debe establecer claramente lo que se espera, los requisitos a cubrir, los recursos que se pueden elegir y el porcentaje de la calificación que le corresponde. Para ello el estudiante deberá realizar un proyecto en el que mostrará el tema elegido y como lo desarrollará, deberá confrontar lo teórico con la realidad nacional y mundial. Lo subirá en la Plataforma para la revisión y corrección del profesor. Una vez aprobado elegirá un recurso (Wiki, líneas de tiempo, mapa mental, video animado, infografía, etc.). En caso de realizar un video previamente elaborará un guión en el procesador de textos de word con duración de 5 minutos, en el que se señale el título, la introducción, el desarrollo y las conclusiones, imágenes, así como la duración en la locución, música y/o efectos de sonido y créditos, efectos de video, transmisión de video. Las imágenes utilizadas pueden ser propias o las existentes en Internet siempre y cuando se respeten los derechos de autor. Debe cuidarse la narración, porque quizá en la grabación se escuchen sonidos no deseados o la voz sea muy baja o incluso se pierda, así que debe editarse la narración. Editar la mezcla narración, efectos de sonido e imágenes. Una vez subido el video debe subirse la evidencia a la Plataforma para calificación.

La mayoría de las actividades en este primer momento fueron asincrónicas, porque aún había clases presenciales, la única actividad sincrónica fue la comunicación por chat de los equipos.

En 2020 lo único que se introdujo fueron las clases por Zoom o por Meet, volviendo los cursos B-learning (semipresenciales) en completamente en línea.

\section{EL EJERCICIO}

Los profesores que cursaron el Diplomado empezaron a ejecutar lo aprendido en 2010 , empezaron a diseñar y planear sus cursos en línea aunque las clases se efectuaban de 
manera semipresencial (B-learning). Para 2020 no resultó ningún problema diseñar el curso, lo único nuevo es que las clases serían totalmente en línea utilizando Zoom o Meet ambos muy amigables e intuitivos.

La primera vez que utilizaron las TIC'S en el aula fue el primer acercamiento que tuvieron los estudiantes con su especialidad es esta asignatura y quizá con el uso, apropiación y explotación de las TIC'S en su formación académica.

En la primera clase presencial, mediante una Laptop y un proyector se les mostró cómo ingresar al aula virtual y la forma en que estaba estructurada, para poder visualizar todo el curso debían darse de alta.

Elaboraron un directorio con nombre, apellidos, correo electrónico y contacto del estudiante, en caso de no contar con una cuenta de Gmail se les pidió que sacaran una.

Como no todos se dieron de alta al mismo tiempo, se abrió una carpeta en Dropbox con las lecturas, así como las instrucciones específicas para la entrega de su primera tarea para compartirla con ellos. Se les envió una invitación en la que se les sugirió crear una cuenta de Dropbox.

Se indicó se hiciera uso de una de las aplicaciones de Gmail: Google docs, con el fin de que pudieran realizar sus primeras tareas y compartirlas con el profesor para su edición.

A los alumnos que no contaban con equipo de cómputo o no tenían acceso a Internet se les compartió el equipo en salas de cómputo o en cubículos para que pudieran realizar sus actividades.

\section{IMPROVISACIÓN}

Las autoridades universitarias reconocieron la necesidad de actualizar a su planta académica con el uso de las TIC'S. La Dirección General de Servicios de Cómputo Académico (DCSCA) fue la institución encargada de diseñar un Diplomado, este se denominó “Aplicaciones de las TIC'S en la enseñanza", se convocó a los profesores interesados y se efectuó en 2010, de este diplomado salieron capacitados más de tres mil profesores de bachillerato y licenciatura, si bien fue un gran logro solo representó el $6.7 \%$ del total de la planta académica 5 .

Aunque se siguió convocando al personal académico para posteriores cursos de actualización tecnológica no hubo mucha respuesta. Eso es muy visible en la cantidad de profesores que se beneficiaron de las aulas virtuales 1750 de un total de 50794. Esa cantidad solo representa $3.44 \%$ de la población de académicos (Portal de Estadística Universitaria, 2021).

¿Qué sucedió ante la contingencia? ¿Cómo se enfrentó el problema de dar clases en línea?

5 De acuerdo al Portal de Estadística Universitaria, (2021) la UNAM contaba con 44348 académicos. 
La cuarentena a causa de la pandemia inició el lunes 23 de marzo, pero con más de una semana de antelación se avisó, es decir, se tenían mínimamente cinco días hábiles para que las autoridades de las respectivas entidades educativas de la UNAM tomarán decisiones sobre cómo se efectuarán las clases y convocaron a los profesores a cursos rápidos de capacitación para la introducción del uso de las TIC'S en la enseñanza.

Cinco días hábiles que los profesores pudieron utilizar para generar un banco de datos con los correos electrónicos de sus alumnos y su número telefónico de celular o de casa, para no perder el contacto con sus alumnos y mantenerse en constante comunicación. Cinco días hábiles en los que pudieron planear en equipo (autoridades-profesor-estudiantes) como se terminaría el semestre. Pero nada de eso sucedió.

¿Cuál fue la respuesta de los profesores? ¿Atendieron a la convocatoria? ¿Estuvieron dispuestos a ser enseñados y continuar con las clases? ¿Su pasión por dar clases los llevó a actualizarse? Las situaciones suscitadas mostraron la vigencia de las palabras de Weber (s/f) “No hay profesor universitario a quien le complazca recordar las polémicas suscitadas con motivo de su nombramiento, pues rara vez fueron gratas..." (p.41) La pandemia dejó muy claro quién ejerce con pasión y por vocación y quien lo hace para tener ingresos seguros. Fue claro qué profesores aman la docencia y están dispuestos al sacrificio y qué profesores viven de la docencia y están dispuestos a sacrificar a otros. Aquí es donde se identifica el ethos académico, ese sentido de pertenencia a, ese compromiso con, esa aceptación de. Quien ama enseñar, no le importa ponerla en primer lugar aunque tenga otras actividades. No se resistirá a los cambios, al contrario estará listo(a) para asimilarlos y facilitar las actividades de sus alumnos.

Los profesores tomaron distintas posiciones. Algunos se negaron de manera rotunda a continuar dando clase de manera virtual, considerando que los estudiantes sabían que esa materia ya estaba perdida, otros profesores acelerarán las actividades para culminar el semestre en los tiempos establecidos. Algunos mostraron falta de interés personal en sus alumnos al no contar con un banco de datos, eso indica que no hubo comunicación virtual previa a la pandemia, y que la entrega de tareas y trabajo final o examen se seguirá efectuando de manera tradicional: impresos en papel y de manera presencial.

Otros profesores optaron por solo conectarse por zoom y dictar su clase de manera tradicional, sin utilizar las herramientas con que cuenta la aplicación, usando el correo electrónico como medio de entrega de trabajos, bajo la idea de "suficiente hago con dar mi clase como para también tenga que aprender a usar la tecnología a estas alturas de mi vida". ${ }^{6}$ Seguramente Rousseau (2008) les hubiera contestado “Maestros celosos, sed sencillos, prudentes, circunspectos; no os deis prisa a obrar, como no sea para estorbar que otros obren..." (p.86). En efecto, Rousseau tiene razón, la prudencia y la sencillez son dos cualidades que un buen profesor debe tener, tanto en su actitud, como en su enseñanza “...el arte de enseñar es,... un don personal del todo independiente de la calidad científica de un sabio...". (Weber, s/f, p.42) Se puede tener el máximo grado académico, un cúmulo de conocimiento, mucha producción académica publicada, el reconocimiento como investigador nacional, pero si no se tiene interés, aptitud, competencia tecnológica y facilidad para enseñar, el

6 En una junta de trabajo en enero de 2021, se pidió a los profesores no dejar solos a los estudiantes, que los apoyaran en este proceso, una profesora contestó de esa manera y fue apoyada por otros miembros del cuerpo docente. 
estudiante se quedará con eso y no con sus credenciales, de presentación.

Entonces ¿no se actualizaron los profesores? Sí, pero en un porcentaje menor al 50\%, tomando como muestra la Facultad de Ciencias Políticas y Sociales de la UNAM, se programaron 31 cursos con la asistencia de al menos 752 profesores (Olivares, 2021) de un total de 1842 miembros de la comunidad académica de esta Facultad (DGAPA, 2020, p. 10) esto representa el $40 \%$ de profesores. Aunque fue un buen ejercicio, un increíble esfuerzo y una excelente actitud, no se puede aprender en unas horas lo que se diseñó, planeo, ordenó, investigó, y ejecutó en un Diplomado de 180 horas.

Son muy oportunas las palabras Rousseau para cerrar esta sección "más deben consistir en acción vuestras lecciones que en discursos, porque con facilidad se olvidan... de lo que han dicho y lo que las han dicho pero no de lo que han hecho y les han hecho" (Rousseau, 2008, p. 91).

\section{BENEFICIOS}

Aunque transitar de clases presenciales a virtuales parece un proceso muy complejo, la verdad es que no sólo lo parece, lo es. Si se hubiera dado de manera gradual, tal y como se había planeado por la Universidad desde 2010, -invitando a que de manera voluntaria los profesores se fueron insertando en el conocimiento apropiación, uso y explotación de las TIC'S, bajo la premisa de que con el tiempo todos los profesores estuvieran actualizados- la pandemia no habría paralizado las actividades de la Universidad. Los estudiantes acostumbrados a un sistema de aprendizaje B-learning se hubieran sentido seguros, tranquilos y cómodos al pasar de un sistema a otro.

Pero como es bien sabido el hubiera no existe, pero deja mucha enseñanza, aprovechar todas las oportunidades que se presenten en las instituciones educativas para capacitar y facilitar el proceso de enseñanza-aprendizaje. Por ello, se debe seguir el consejo de Rousseau (2008) "Maestros, dejaos de puerilidades, sed virtuosos y buenos, y grábense vuestros ejemplos en la memoria de los alumnos..." (p. 96).

Uno de los beneficios de este tipo de enseñanza es que los estudiantes se sienten muy emocionados e incentivados a generar un producto no perecedero ${ }^{7}$ en el que resumen su aprendizaje de una manera creativa, lúdica y que sirve para explicar de manera sencilla términos científicos. Se identifican y se integran de inmediato al curso en línea, se vuelven muy participativos incluso los estudiantes más tímidos. Se da un flujo de comunicación continuo, abierto y respetuoso entre el profesor y el alumno.

En este tipo de enseñanza genera muchas satisfacciones más aún cuando el profesor no improvisa y se compromete y el estudiante lo disfrute y responde de manera positiva y propositiva, el gusto por la clase es recíproco no por la calificación, ni por los créditos, sino por lo que se aprende, lo que se entiende, lo que se comprende, lo que se debate, "La vocación se acompaña de la pasión" (Weber, s/f, p. 43).

7 Por ejemplo, en la asignatura "Estado Sistema y Poder Político" a cargo de una sola profesora los estudiantes han publicado más de 100 videos, más de 100 mapas mentales y aproximadamente 30 wikis. 


\section{A MODO DE CONCLUSIÓN}

En el arte de enseñar convergen una serie de factores que no necesariamente tienen relación con los grados académicos, los nombramientos o los reconocimientos, más bien con la capacidad de aceptar las limitaciones y proceder a erradicarlas. Admitir que se debe invertir más tiempo en la actualización, capacitación y formación y hacerlo. Conocer a los estudiantes, sus capacidades, habilidades y carencias e integrarlos. Tener una relación más humana y menos mecánica. Ver la enseñanza como una forma de vida y no como un medio para vivir. Estar preparados para las contingencias y verlas como oportunidades para crecer. Planear con antelación lo que se va a enseñar y cómo se va a enseñar. Conocer y apropiarse de las Tecnologías de la Información y Comunicación (TIC 其 S), y adecuarlas a las especialidades respectivas. No que la pandemia o cualquier otra contingencia sea el factor decisivo para usarlas o dejar de hacerlo. Armarse de paciencia y transmitirla a los estudiantes. Facilitar la apropiación del conocimiento y generar una educación dialogal. Los resultados del ejercicio indican cómo el arte de enseñar está estrechamente relacionado con la vocación, la pasión, la creación, la flexibilidad, el compromiso, la apropiación de métodos, instrumentos o herramientas que ayuden al estudiante a pensar, reflexionar, proponer, disfrutar, generar e interpretar y entender su realidad

\section{REFERENCIAS}

Alvar, (2020). Convocatoria a reunión informativa virtual. [Correo electrónico].

Bronowski, J. (1978). El sentido común de la Ciencia. Barcelona: Península.

Centro de Estudios Políticos, (2020). Convocatoria a reunión informativa virtual. [Correo electrónico].

Dirección General de Asuntos del Personal Académico (DGAPA), (2020). Estadísticas del personal académico 2020. Recuperado de URL: https://bit.ly/3vpmoWt

El Informador, (2011). Capacita la UNAM a sus maestros en tecnologías informáticas. Informador.Mx. Recuperado de https://bit.ly/3pLFfte

Facultad de Ciencias Políticas y Sociales. (2015). Funciones de las Comisiones del $\mathrm{H}$. Consejo Técnico. Recuperado de https://bit.ly/2UOdYYt

Freire, P. (2007). La educación como práctica de la libertad. México: Siglo XXI.

Gobierno de México, Secretaría de Comunicaciones y Transportes. (2019). Anexo 4: Sitios públicos por conectar. Recuperado de https://bit.ly/3xtWMcr

Instituto Nacional de Estadística y Geografía (INEGI). (2020). Encuesta para la Medición del Impacto COVID-19 en la Educación (ECOVID-ED) 2020. Recuperado de https://bit. ly/2U1S1rZ

Montesquieu, Ch. (2010). El Espíritu de las Leyes. México: Porrúa.

Olivares, (2021). Consulta. [Correo electrónico].

Platón. (1988). IV República. España: Gredos.

Presidencia de la República, México. (2019). Plan Nacional de Desarrollo 2019-2024. Recuperado de https://bit.ly/3cxc4Vp

Portal de Estadística Universitaria, (2021). Series Estadísticas UNAM, 2000 a 2021. 
Areté, Ethos académico, TIC's y pandemia en México

Recuperado de https://bit.ly/3cwO3Oo

Prensa total. (28 de marzo de 2019). Niño utiliza luz del poste para realizar sus tareas escolares (Video). Recuperado de https://bit.ly/2Ssa2PK

Rousseau, J.J. (1965). Las confesiones. Madrid: Adat.

Rousseau, J.J. (2008). Emilio o de la educación. México: Grupo Editorial Éxodo.

Rousseau, J.J. (s/f). Emilio o de la educación. Recuperado de https://bit.ly/3iAN9V6

Russell, B. (1983). La perspectiva científica. Madrid: Sarpe.

Secretaría de Educación Pública, (2020). Principales cifras del sistema educativo nacional, México. Recuperado de https://bit.ly/35bhNMH

Secretaría de Gobernación. (16 de abril de 2021). Diario Oficial de la Federación. Recuperado de https://bit.ly/3zo5wSQ

Sietemasumma. (2O20). Experiencias docentes - Como llegar a los alumnos que no tienen internet (Video). Recuperado de https://bit.ly/3izgi2G

Weber, M. (s/f). El político y el científico. Recuperado de https://bit.ly/3vgXfNe

VOLUMEN III/ NÚMERO 1/ AÑO 2/ISSN 977245257580/ PÁGINAS 39-54/RECIBIDO: 17-05-2021/ APROBADO: 1-06-2021/ www.revpropulsion.cI

54 